\title{
Correction to: Improvement of recycled concrete aggregate using alkali-activated binder treatment
}

\author{
Nattapong Damrongwiriyanupap • Akaraphol Wachum • Kamonphop Khansamrit • \\ Satakhun Detphan · Sakonwan Hanjitsuwan • Tanakorn Phoo-ngernkham • \\ Piti Sukontasukkul $\cdot$ Long-yuan Li $\cdot$ Prinya Chindaprasirt
}

Accepted: 3 January 2022/Published online: 11 January 2022

(C) RILEM 2022

Correction to: Materials and Structures (2022) 55:11

https://doi.org/10.1617/s11527-021-01836-1

In this article the affiliation details for Kamonphop Khansamrit were incorrectly given as 'Program of Civil Technology, Faculty of Industrial Technology, Lampang Rajabhat University, Lampang 52100, Thailand' but should have been 'Sustainable Construction Material Technology Research Unit, Department of

Civil Engineering, Faculty of Engineering and Technology, Rajamangala University of Technology Isan, Nakhon Ratchasima 30000, Thailand'.

The original article has been corrected.

Publisher's Note Springer Nature remains neutral with regard to jurisdictional claims in published maps and institutional affiliations.

The original article can be found online at https:// doi.org/10.1617/s11527-021-01836-1.

N. Damrongwiriyanupap

Department of Civil Engineering, School of Engineering, University of Phayao, Phayao 56000, Thailand

A. Wachum $\cdot$ K. Khansamrit $\cdot$ S. Detphan .

T. Phoo-ngernkham ( $\bowtie)$

Sustainable Construction Material Technology Research Unit, Department of Civil Engineering, Faculty of Engineering and Technology, Rajamangala University of Technology Isan, Nakhon Ratchasima 30000, Thailand e-mail: tanakorn.ph@rmuti.ac.th

\section{S. Hanjitsuwan}

Program of Civil Technology, Faculty of Industrial Technology, Lampang Rajabhat University,

Lampang 52100, Thailand

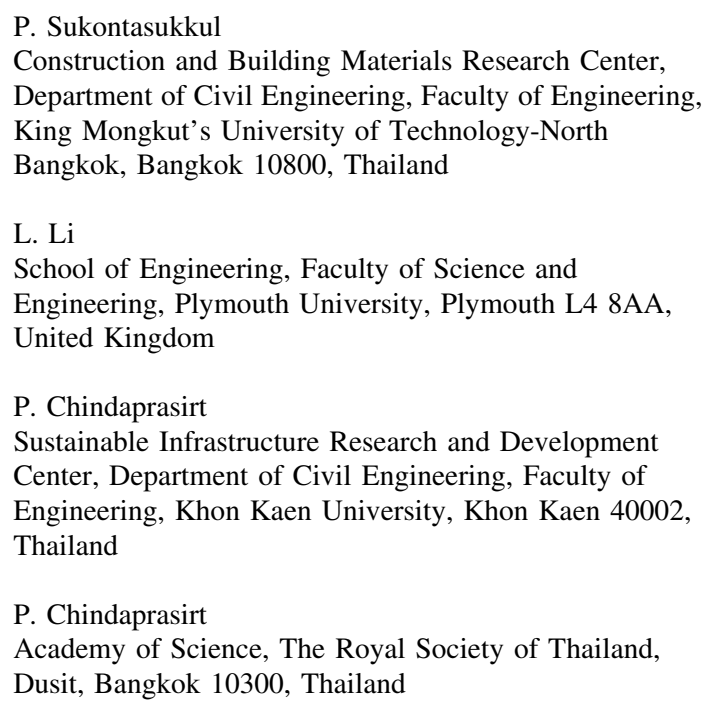

